Published in final edited form as:

Semin Immunopathol. 2014 January ; 36(1): 93-102. doi:10.1007/s00281-013-0400-x.

\title{
Dendritic cells in atherosclerosis
}

\author{
Manikandan Subramanian and \\ Department of Medicine, Columbia University, 630 West 168th Street PH9-406, New York, NY \\ 10032, USA
}

\section{Ira Tabas}

Department of Medicine, Columbia University, 630 West 168th Street PH9-406, New York, NY 10032, USA. Department of Pathology and Cell Biology, Columbia University, 630 West 168th

Street PH9-406, New York, NY 10032, USA. Department of Physiology, Columbia University, 630 West 168th Street PH9-406, New York, NY 10032, USA

Manikandan Subramanian: ms4144@columbia.edu

\begin{abstract}
Atherosclerosis is a chronic inflammatory disease with activation of both the innate and adaptive arms of the immune system. Dendritic cells (DCs) are potent activators of adaptive immunity and have been identified in the normal arterial wall and within atherosclerotic lesions. Recent evidence points to a functional role for DCs in all stages of atherosclerosis because of their myriad functions including lipid uptake, antigen presentation, efferocytosis, and inflammation resolution. Moreover, DC-based vaccination strategies are currently being developed for the treatment of atherosclerosis. This review will focus on the current evidence as well as the proposed roles for DCs in the pathogenesis of atherosclerosis and discuss future therapeutic strategies.
\end{abstract}

\section{Keywords}

Dendritic cells; Atherosclerosis; Tregs; Efferocytosis

\section{Introduction}

Atherosclerosis is a disorder in which the sub-endothelial retention of apolipoprotein Bcontaining lipoproteins in focal areas of the arterial tree triggers a chronic, nonresolving inflammatory disorder mediated by activation of the innate and adaptive arms of the immune system [1]. The retained lipoproteins, perhaps after oxidative modification, mediate endothelial cell activation and recruitment of monocytes into the subendothelial region or intima. The newly recruited monocytes differentiate into macrophages and DCs, many of which ingest the retained lipoproteins to become cholesteryl ester-laden "foam cells." The macrophages and DCs, along with T cells and other immune cells, mount a maladaptive, nonresolving immune response that promotes progression of the atherosclerotic process [2]. Other features of developing atherosclerotic lesions include the accumulation of myofibroblastic-like vascular smooth muscle cells and expansion of the extracellular matrix proteins, notably proteoglycans, collagen, and elastin. The inflammatory environment, coupled to endoplasmic reticulum (ER) stress, oxidative stress, and likely other processes, can eventually lead to apoptosis of intimal cells as lesions progress. When these apoptotic cells are not efficiently cleared by neighboring phagocytes (efferocytosis), they become

(C) Springer-Verlag Berlin Heidelberg 2013

Correspondence to: Manikandan Subramanian, ms $4144 @$ columbia. edu. 
secondarily necrotic and, together with other processes that trigger primary cell necrosis, promote the formation of the so-called necrotic core [2]. In humans, the presence of a necrotic core in an atherosclerotic lesion, along with thinning of fibrous scar, or "cap," that normally forms over the core, predicts a "vulnerable" plaque phenotype [3] that is susceptible to plaque rupture and luminal thrombosis. This series of events accounts for the majority of plaques that trigger acute myocardial infarction, unstable angina, sudden cardiac death, and stroke.

Dendritic cells (DCs) are uniquely poised to serve at the interface of innate and adaptive immune system and are the most potent cells to activate both naïve and memory $\mathrm{T}$ cells. The identification of DCs in human [4] and mouse [5] vascular wall has stimulated tremendous interest in the role of these cells in the pathogenesis of several acute and chronic vascular disorders, including atherosclerosis. How DCs influence the initiation and progression of atherosclerosis is not clear, but their roles in presenting antigen to and activating $\mathrm{T}$ cells and secreting cytokines, and perhaps also their ability to become foam cells and to participate in efferocytosis, suggest that DCs have major influence on the pathogenesis of atherosclerosis. This review will focus on the origin and functional role of DCs in the pathogenesis of atherosclerosis and discuss novel approaches of targeting DCs as a therapeutic strategy in atherosclerosis.

\section{Identification and characterization of vascular wall DCs}

Lymphoid tissue DCs have been phenotypically classified as classical DCs (cDCs) and plasmacytoid DCs (pDCs) based on cell surface markers and functional criteria. However, the phenotypic identification of DCs in nonlymphoid tissues including within the atherosclerotic plaque has been an area of considerable confusion both in humans and mice because of the overlapping nature of the cell-surface markers used to characterize them, differences in expression markers based on their developmental origin (discussed in the next section), and phenotypic cellular plasticity. For example, CD11c, which is considered a marker of classical DCs in lymphoid tissues, can also be expressed by macrophages in an inflammatory microenvironment such as in the setting of atherosclerosis. A refined approach to identify DCs uses multiple cell-surface markers simultaneously. For example, DCs are CD11c $\mathrm{c}^{\mathrm{hi}}, \mathrm{MHC}-\mathrm{II}^{\mathrm{hi}}$, and can be, CD11b ${ }^{ \pm}, \mathrm{F} 4 / 80^{ \pm}, \mathrm{CD}_{103}{ }^{ \pm}, \mathrm{DEC}-205^{ \pm}, \mathrm{Clec} \mathrm{a}^{ \pm}$, and Mertk $^{\mathrm{lo} /-}$. More recently, transcriptional profiling have added impetus to the use of additional markers such as Flt3, c-Kit, CD272, and CD26, which have been demonstrated to be expressed exclusively by classical DCs and not by several types of tissue macrophages [6]. There are several drawbacks of this approach, including (a) cell-surface marker analysis by flow cytometry, requires dissociation of cells from tissues using enzymatic approaches, which can introduce artifacts. For example, some proteins are more susceptible to cleavage or degradation upon enzymatic digestion [7] and (b) localization of distinct subsets of DCs in the vascular wall or atherosclerotic plaque cannot be determined because of the nature of the assay. However, newer techniques such as "histocytometry" [8], which combines multiplex antibody labeling and powerful analytical microscopy, may overcome these limitations and future studies in this direction are highly warranted.

In vitro studies have demonstrated that macrophage foam cells may adopt a DC-like phenotype, including expression of CD11c and MHC-II [9]. However, whether these cells actually exist in atherosclerotic lesions and have the functional capabilities of DCs, notably the ability to present antigen to naïve T cells, is not known. In general, the phenotypic promiscuity of DCs demands that they be defined functionally in terms of their superior ability to present antigens to and activate native T cells. Thus, it is imperative that newly identified subsets of cells hypothesized to be DCs be loaded with model antigens and then 
tested for their ability to present antigen to activate naïve antigen-specific transgenic $\mathrm{T}$ cells. The ovalbumin-based OVA-OT I/OT II experimental model is often used for this purpose.

\section{Origin of arterial wall DCs}

DCs have been identified in the arterial wall of both humans and mice [5, 10]. Interestingly, they are present in higher numbers in the atherosclerosis-prone regions, such as the lesser curvature of the aorta [11]. These regions are exposed to high shear-stress blood flow, and so shear-stress signals might be involved in DC recruitment. However, the specific molecular mechanisms or chemokine receptors involved in recruiting DCs or their precursors to non-atherosclerotic aorta have not yet been identified. In a seminal study, Choi et al. [12] demonstrated that DCs in normal aorta are predominantly located in the intima and can be classified into at least two developmentally distinct subsets, namely, $\mathrm{CD} 11 \mathrm{c}^{+} \mathrm{CD} 11 \mathrm{~b}^{-} \mathrm{CD} 103^{+}$and CD11 $\mathrm{c}^{+} \mathrm{CD} 11 \mathrm{~b}^{+} \mathrm{CD} 103^{-}$DCs. The $\mathrm{CD} 103^{+}$subset in the aortic wall expanded after injection of the DC developmental factor Flt3 $\mathrm{L}$ and was specifically lost in $\mathrm{Flt}^{-/-}$mice, demonstrating that this subset was derived from classical Flt3L-dependent pre-DC precursors. By contrast, the $\mathrm{CD} 11 \mathrm{~b}^{+} \mathrm{CD} 103^{-}$subset was dependent on the monocyte-related growth factor M-CSF, suggesting derivation from circulating monocyte precursors. Interestingly, the numbers of both subsets expanded rapidly in the intima of atherosclerotic lesions after introduction of hypercholesterolemia into the model. However, the $\mathrm{CD} 11 \mathrm{~b}^{+} \mathrm{CD} 103^{-}$subset accounted for most of the intimal DCs, suggesting that monocyte-derived DCs contribute most towards expansion of DC numbers in progressing atherosclerotic lesions. However, the predominant monocyte subset that serves as the precursor of these DCs is not yet clear, with some studies suggesting that Ly6c ${ }^{\mathrm{lo}}$ monocytes preferentially differentiate to lesional DCs [13] and others suggesting that they are derived from Ly6c ${ }^{\text {hi }}$ monocytes [14]. The observation that $\mathrm{Cx}_{3} \mathrm{crl}^{-/-}$mice have decreased accumulation of lesional DCs suggests that CX3CR1 may play a role in DC recruitment into lesions [15]. However, it is important to note that CX3CR1 is also used by monocytes to adhere to the vascular wall, and so the decrease in intimal DCs in $\mathrm{Cx} 3 \mathrm{crl}^{-/-}$mice may result primarily from decreased monocyte recruitment, which then secondarily suppresses DC differentiation. Thus, further studies are necessary to understand the specific chemokine receptors that are involved in recruitment of DCs into atherosclerotic lesions. pDCs are another DC subset that is present in atherosclerotic lesions, albeit in smaller numbers than classical DCs [16]. pDCs are derived from the so-called common DC precursor and, unlike classical DCs, express low levels of CD11c and MHC-II and high levels of PDCA-1 and SiglecH. A recent study described another specific subset of DCs, CCL17 $7^{+}$DC, which was present in atherosclerotic lesions but not the healthy vascular wall [17]. These lesional CCL $17^{+}$DCs expressed markers of DC maturation, notably high levels of MHC-II, CD40, CD80, and CD86. Currently, it is unclear whether these CCL17 ${ }^{+}$DCs represent a developmentally distinct subset. Apart from DCs originating from pre-DC precursors and monocytes, there is evidence for local proliferation of CD11 $\mathrm{c}^{+} \mathrm{DCs}$ in nascent and early lesions, as demonstrated by BrdU labeling [18]. Proliferation was shown to be dependent on GM-CSF [18], a cytokine that is used experimentally to differentiate DCs in vitro from peripheral blood monocytes or bone marrow hematopoietic stem cells. Given the recent demonstration that differentiation of inflammatory DCs from monocytes is not dependent on GM-CSF [19], it will be interesting to determine whether GM-CSF-dependent proliferation is restricted to a specific subset of DCs in atherosclerotic lesions. Finally, the recent identification of a zinc finger transcription factor, Zbtb46, which is specifically expressed in classical DCs and not in pDCs or monocytes [20,21], may help elucidate the relative contribution of classical DCs derived from pre-DC precursors versus those derived from monocytes in the context of atherosclerosis. For example, breeding the Zbtb46-DTR mouse model [21], which enables depletion of DCs expressing Zbtb46, into an atherosclerosisprone background may be a useful model in this regard. 


\section{Functional role of DCs in atherosclerosis}

\section{Role of DCs in lipid uptake and lipid metabolism}

As mentioned earlier (Fig. 1), a subpopulation of cholesteryl ester-laden foam cells in atherosclerotic lesions appears to be derived from DCs. The mechanism by which DCs internalize lipoproteins to become foam cells remains to be determined, but the process likely involves multiple processes including macropinocytosis, receptor-mediated endocytosis, scavenger receptor-mediated uptake, direct uptake from circulation via dendritic processes that extend into the vascular lumen, and efferocytosis of cholesterol-rich apoptotic cells. Interestingly, depletion of vascular DCs in CD11c-DTR mice following injection of diphtheria toxin decreases the accumulation of lipids in nascent lesions, suggesting that DCs are an important mediator of early lesional lipid accumulation [22]. The functional significance, if any, of lipid accumulation by DCs is not known and will be discussed below.

Interestingly, apart from the role of DCs in lipid uptake in early lesions, several lines of evidence suggest that DCs in other sites might be involved in regulating systemic cholesterol levels. For example, in Western diet-fed $\mathrm{Ldlr}^{-/-}$and $A \mathrm{poe}^{-/-}$mice in which the lifespan of DCs was enhanced by CD11c-specific transgenic expression of the anti-apoptotic protein Bcl-2, there was a decrease in the level of VLDL and LDL cholesterol [23]. Conversely, acute ablation of DCs upon injection of diphtheria toxin in a CD11c-DTR mice led to an increase in plasma cholesterol levels in $\mathrm{Ldlr}^{-/-}$and $\mathrm{Apoe}^{-/-}$mice [23]. The precise mechanisms by which DCs regulate systemic cholesterol levels is not known, but recent studies suggest that DCs might influence cholesterol absorption from the intestine as well as fecal excretion of sterols [24]. These data illustrate the extent of immune-metabolism crosstalk and highlight the central role of immune cells in modulating metabolic disorders.

\section{Role of lipids in modulation of DC function}

The macrophage has been the predominant lesional cell type studied to assess the affect of lipid accumulation on cell function. For decades, investigators had assumed that cholesterol accumulation promoted macrophage "activation." However, Glass and colleagues have recently presented in vitro evidence that cholesterol accumulation by macrophages can actually promote an anti-inflammatory response through activation of the transcription factor LXR by desmosterol [25]. Whether this pathway exists in cholesterol-loaded DCs has not yet been reported. Other macrophage consequences of lipid accumulation that may or may not apply to DCs include the ability to efflux cholesterol and/or possibly emigrate from lesions, which may promote the clearance of extracellular lipid from developing lesions. Finally, oxidation products of sterols and other lipoprotein-derived lipids could potentially trigger inflammation, oxidative and ER stress, and/or cell death in lesional DCs as they are thought to do in lesional macrophages.

In terms of how lipids may affect functions more specific to DCs, studies have shown that native LDL as well as the oxidatively modified forms of LDL can induce DC maturation, with upregulation of costimulatory molecules and inflammatory cytokines, in a manner that could influence the migratory and T cell-stimulatory capacity of DCs [26-28]. In this context, it is interesting to note that DCs under hyperlipidemic conditions have normal T cell stimulatory capacity [29], while their ability to migrate from peripheral tissues to secondary lymphoid organs is severely impaired [30]. This could have multiple implications in atherosclerosis: (a) impaired migration could impede the inflammation resolution function of DCs, such as cholesterol efflux, clearance of dead cells, and antigen presentation to T cells, which may be critical in inducing $\mathrm{T}$ cell tolerance to self or modified self antigens in atherosclerotic plaques; (b) local retention and maturation of DCs could promote the local 
secretion of inflammatory cytokines, leading to enhanced monocyte and $\mathrm{T}$ cell recruitment; (c) local activation or reactivation of antigen-specific T cells by antigen-presenting DCs could lead to exacerbation of local inflammation; and (d) secretion of collagenases and matrix metalloproteases by mature DCs could promote collagen and extracellular matrix degradation, leading to thinning of the protective fibrous cap and a vulnerable plaque phenotype.

The inability of DCs to migrate under hyperlipidemic conditions appears to be due to deficient upregulation of the migratory chemokine receptor CCR7. The evidence for this stems from the observation that surgical transplantation of diseased aorta into normocholesterolemic animals led to regression of atherosclerotic lesions with emigration of CD11 $\mathrm{c}^{\text {hi }}$ cells expressing high levels of CCR7 [31]. Moreover, neutralization of CCL19 and CCL21, ligands for CCR7, prevented the regression of lesions in the surgical aortic transplant model demonstrating that the emigration was dependent on expression of CCR7 [31]. However, when lesion regression was induced by treating $A p o e^{-/-}$mice with viral vectors encoding Apoe, CCR7 did not affect lesional myeloid cell numbers [32]. Moreover, $\mathrm{Ccr}^{-/-} \mathrm{Apoe}^{-/-}$tended to have smaller lesions, arguing against a role for CCR7 in myeloid cell egress [32]. However, it is important to note that CCR7 is also important for homing of T cells [33], which could have influenced the phenotype of the CCR7-deficient lesions. Interestingly, recent studies in mice demonstrated that treatment with statins led to lesion regression, which was associated with increased expression of CCR7 in lesional cells [34]. While the primary beneficial effect of statins is related to their ability to lower plasma apoBcontaining lipoproteins, it is theoretically possible that additional, incremental benefit may be derived by restoration of the inflammation resolution function of DCs. All of these studies call for additional studies and improved models to understand the mechanisms and consequences of CCR7 regulation and other factors that may affect DC trafficking, such as cellular guidance signals [35], during atherosclerosis progression.

\section{DC maturation, antigen presentation, and atherosclerosis}

Prior to antigen exposure, DCs exist in the immature state, characterized by the capacity to capture antigen but not yet expressing high levels of MHC-I/II antigen presenting module or the T cell costimulatory molecules CD80, CD86, and CD40. Upon TLR-mediated activation, DCs undergo the process of maturation, which is associated with downregulation of several modes of antigen capture, notably phagocytosis and efferocytosis, upregulation of MHC-I, MHC-II, CD80, CD86, and CD40, and migration to draining lymph nodes for antigen presentation to nodal $\mathrm{T}$ cells. Interestingly, both human and animal studies have demonstrated that mature DCs accumulate in the atherosclerotic plaques with lesion progression [10]. This is consistent with the idea that DC migration is defective under hypercholesterolemic conditions as described above. The signals that contribute to DC maturation in atherosclerotic lesions are not known, but several candidates include inflammatory cytokines, DNA and RNA fragments derived from necrotic cells, and cholesterol crystals. DC maturation is associated with pro-inflammatory cytokine secretion as well as the ability to robustly activate naïve $\mathrm{T}$ cells in an antigen-specific manner, both of which are known to accelerate atherosclerosis [36]. Indeed, early studies demonstrated that atherosclerosis is decreased in mice lacking the T cell costimulatory molecules CD80 and CD86 (CD80 $\left.{ }^{-/-} \mathrm{CD}^{-1-}\right)$, which are upregulated during DC maturation, and in mice deficient in CD74 (MHC-II associated invariant chain), which regulates antigen loading on MHC-II [37, 38]. These data suggested that DC maturation and antigen presentation to T cells led to a pro-atherogenic phenotype. However, deletion of CD80/CD86 is associated with severe systemic defect in regulatory T cell (Treg) development [39], a subset of T cell that is known to be atheroprotective [40]. Similarly, deficiency of CD74 is associated with a dramatic decrease in the number of peripheral $\mathrm{T}$ cells [38] which could have secondary 
consequence on atherosclerosis independent of DC function. In this context, a more specific way to decrease the ability of DCs to present antigen to and activate T cells can be accomplished by blocking DC maturation through DC-specific knockdown of MyD88 $\left(\mathrm{Cd} 11 \mathrm{cCr} \mathrm{C}^{+} \mathrm{Myd} 88^{f l / f l}\right)$ [41]. When these mice were placed on an atherosclerosis background, there was defective activation of both effector T cells (Teff) and Tregs in lesions, but the net effect was increased atherosclerotic lesion development [42]. These data demonstrate that DC maturation and antigen presentation play a major role in the development of atheroprotective Tregs, which has a dominant effect over the proatherogenic role of DC-activated Teff cells.

Other key questions related to DC-mediated T cell activation in the setting of atherosclerosis pertains to the identity of the antigen(s) in atherosclerosis, the site of antigen acquisition by DCs, as well as the site of DC-Tcell interaction. Among the lesional antigens that have been hypothesized to be important are oxidized LDL, Hsp60, Hsp65, and $\beta 2$-glycoprotein I [43]. One idea is that lesional DCs acquire these and/or other antigens by macropinocytosis, scavenger receptor mediated uptake, or efferocytosis of antigen containing dead cells and then process and present those antigens on their MHC-I and MHC-II modules. Alternately, circulating DCs, peripheral tissue DCs, or lymphoid-tissue DCs may capture and then present circulating atherosclerosis-relevant antigens, such as oxidized LDL. It is interesting to note that in the aforementioned model of defective DC maturation [42], Treg numbers were decreased not only in the atherosclerotic lesions and in draining mediastinal and iliac lymph nodes, but also in nondraining inguinal lymph nodes. These data raise the possibility that DCs acquire certain antigens outside of atherosclerotic lesions per se.

The primary site of DC-mediated antigen presentation to T cells in atherosclerosis is an active area of investigation. The demonstration of oligoclonal expansion of T cells [44], as well as the finding that $\mathrm{T}$ cells are in close proximity to DCs as imaged in fixed aortic tissues [45] and in live images of aortic explants [46], have raised the interesting possibility that the atherosclerotic intima itself may be a site of antigen presentation and $\mathrm{T}$ cell activation. However, it is unlikely that this possible scenario represents the site of priming of naïve $\mathrm{T}$ cells, because the emigration of naïve $\mathrm{T}$ cells into peripheral tissues is limited. Rather, DCs may interact with activated/ memory T cells in lesions, which is consistent with the expression of activation markers by the T cells that interact with intimal DCs [46]. Moreover, in an aortic explant model, only T cells derived from hypercholesterolemic animals demonstrate interaction with aortic DCs [46]. These date reinforce the idea that the $\mathrm{T}$ cells that directly interact with DCs in lesions are pre-activated. The interaction of mature DCs with activated/memory $T$ cells could have pathologically and clinically relevant consequences because of elicitation of a local inflammatory response, especially in advanced lesions where these DCs are sequestered because of deficient emigration. Another potential site of DC-mediated antigen presentation to T cells could be the arterial tertiary lymphoid organs (ATLO), which have been described in the adventitia adjoining advanced atherosclerotic lesions of mice [47]. These are sites with high endothelial venules, follicular DCs, and well-defined T and B cell areas. The mechanisms by which these ATLOs are formed are currently unknown. However, lymphotoxin- $\beta$ receptor-expressing vascular smooth muscle cells have been hypothesized to play a role in their organization [47].

\section{Role of DCs in maintaining Treg cell homeostasis}

Tregs are a subset of $\mathrm{CD} 4^{+} \mathrm{T}$ cells that suppress inflammation in atherosclerosis by inhibiting pro-atherogenic Th1 T cell responses [40] and by suppressing activation of endothelial cells [48] and macrophages via secretion of anti-inflammatory cytokines such as TGF- $\beta$ and IL-10 $[42,49]$. The current literature suggests that the atheroprotective response is mediated by both natural, thymus-derived as well as by adaptive or inducible Tregs, 
which are derived by activation of naïve T cells in peripheral lymph nodes [50]. However, the relative contribution of natural vs. adaptive Tregs in suppressing inflammation in atherosclerosis is not known. The studies in this area are limited because of the lack of specific markers to distinguish the two populations [51]. The methylation status of CpG-rich Treg-specific demethylated region of the FoxP3 locus is the most precise marker of adaptive Tregs, because they are predominantly demethylated at this region while this region in natural Tregs is methylated. However, such analyses are not amenable in the context of atherosclerosis because of the small numbers of vascular Tregs that can be isolated from atherosclerotic aorta. In this context, recent demonstration of markers such as Helios [52] and Neuropilin [53] for distinguishing natural vs. adaptive Tregs warrants further investigation in the setting of atherosclerosis.

The current paradigm suggests that adaptive Treg cell development is favored by the presentation of antigen by immature DCs in a noninflammatory environment [54]. However, we recently demonstrated that MyD88 signaling in DCs, which is critical for DC maturation, is also important for generating a protective Treg cell response in the context of atherosclerosis [42]. This finding is consistent with recent data in the literature showing that the development of both Teff as well as Tregs from naïve $T$ cells requires costimulation via CD80/CD86 [54], which is upregulated upon DC maturation. We also showed that the Tregsecreted TGF- $\beta$ represses MCP-1 production by macrophages, thereby inhibiting the recruitment of inflammatory Ly6 $\mathrm{c}^{\text {hi }}$ monocytes into atherosclerotic intima [42]. These data indicate that in early atherosclerosis, DC-mediated activation of T cells is dominated by an atheroprotective Treg response. However, the evidence that DCs in advanced lesions have a migratory defect (above) raises the interesting question as to whether lesional DCs in this setting can promote the formation of Tregs. This is especially important, because in early atherosclerosis, DC-mediated activation of T cells likely occurs after migration to draining lymph nodes, where a non-inflammatory environment, with low levels of IFN- $\gamma$ and IL-12, might favor the development of atheroprotective Tregs. In contrast, in advanced atherosclerosis, wherein DC emigration is defective [30], antigen presentation presumably occurs under inflammatory conditions, which might result in strong costimulatory signaling and the development of pro-atherogenic Teff cells. The experimental testing of these hypotheses will require the development of models in which DC maturation could be blocked in a temporal manner. For example, one could utilize an inducible Cre to delete MyD88 in CD11 $\mathrm{c}^{\text {hi }}$ cells only in advanced atherosclerosis. In addition, temporal inducible expression of CCR7 in advanced lesional DCs might rescue the migration defect and thus further test the hypotheses mentioned above.

There is also evidence for specific subsets of lesional DCs that can preferentially activate atheroprotective Treg cells or specifically inhibit their development. For example, the $\mathrm{CD}_{103^{+}}$DCs in lesions have been demonstrated to be tolerogenic DCs and to promote the development of Tregs [12]. These DCs are dependent on Flt3-Flt3L interaction for their development, and their loss in Flt3 ${ }^{-/-} \mathrm{Ldlr}^{--}$mice resulted in decreased aortic Tregs, decreased IL10 production, increased production of pro-inflammatory cytokines TNF- $a$ and IFN- $\gamma$, and exacerbation of atherosclerosis [12]. It is interesting to note that $\mathrm{CD}_{103^{+}} \mathrm{DCs}$ in the gut have also been demonstrated to be potent inducers of Treg cell differentiation, which is partly dependent upon their ability to secrete TGF- $\beta$ and retinoic acid [55], cytokines which play a key role in peripheral Treg differentiation. Moreover, lung CD103 ${ }^{+}$DCs, via secretion of CCL22, has been demonstrated to be important in the recruitment of circulating Tregs [56]. This raises the interesting possibility that vascular $\mathrm{CD} 103^{+} \mathrm{DCs}$ might utilize a TGF- $\beta /$ retinoic acid pathway and CCL22 to induce differentiation of peripheral Tregs and recruit circulating thymus-derived natural Tregs, respectively, into early atherosclerotic lesions. 
In contrast to the $\mathrm{CD}_{103^{+}}$subset of DCs, CCL17 ${ }^{+} \mathrm{DCs}$, which are also present in atherosclerotic lesions, appear to restrain Treg development [17]. In particular, CCL17 acting on CCR4 on T cells prevents the differentiation of naïve T cells to Tregs and promotes apoptosis of Tregs [17], and $C C L 17^{-/-}$Apoe $e^{-/-}$mice show an expansion of lesional Tregs and decrease in lesional macrophages and atherosclerotic lesion size. As described earlier, it is not yet clear whether the CCL $17^{+}$DCs are a developmentally distinct subset of DC or mature DCs that have been induced to express CCL17.

In summary, DCs appear to play a central role in maintaining Treg homeostasis in developing atherosclerotic lesions. The balance between Treg and Teff activation is a critical factor in determining whether the inflammatory component of atherosclerosis becomes exacerbated, leading to plaque progression, or whether lesional inflammation resolves. DC/ Treg-mediated inflammation resolution could be a major factor in plaque stabilization or, in the setting of correction of hyperlipidemia, and plaque regression.

\section{Role of pDCs in atherosclerosis}

pDCs have been described in the shoulder regions of both human and mouse atherosclerotic plaques and constitute only a small proportion of the total intimal DC population [57]. However, pDCs are potent secretors of the type 1 interferons IFN- $\alpha$ and IFN- $\beta$, both of which are known to be pro-atherogenic [58]. Moreover, the levels of IFN- $a$ in human plaque have been shown to correlate positively with plaque vulnerability. In addition, INF-a has been shown to induce vascular smooth muscle cell apoptosis [57], which might promote detrimental thinning of the fibrous cap, and to sensitize DCs to TLR ligands, which induce pro-inflammatory cytokine production [59]. However, whether pDCs play a pro-atherogenic role is not clear, because depletion of pDCs using an antibody against bone marrow stromal cell antigen 2 led to aggravation of atherosclerosis in a Western diet fed $\mathrm{Ldlr}^{-/-}$mouse model [60], whereas in an Apoe ${ }^{-/-}$mouse model there was atheroprotection [16]. Thus, further studies are required to understand the role of pDCs in atherosclerosis.

\section{DC efferocytosis—potential roles in antigen acquisition, inflammation resolution, and necrotic core formation}

Efferocytosis is the process by which phagocytes recognize and clear apoptotic cells in a non-inflammatory manner. Immature classical DCs, which are present in early atherosclerotic lesions, and $\mathrm{CD}_{103^{+}} \mathrm{DCs}$ are potent efferocytes, which raises interesting questions about the importance of this process as a mechanism for antigen acquisition by DCs and subsequent T cell activation. DCs constantly sample the microenvironment for antigens using a multitude of processes including macropinocytosis, receptor-mediated endocytosis, phagocytosis, and efferocytosis. Following uptake, antigenic proteins or lipids are processed and presented on MHC-I or MHC-II to elicit either activation of antigenspecific $\mathrm{T}$ cells or to induce $\mathrm{T}$ cell tolerance, depending on the specific context. DC efferocytosis-mediated antigen presentation has been hypothesized to be critical in eliciting an immune response in several viral and autoimmune diseases [61]. However, this hypothesis remains to be proven in any context, including atherosclerosis as the molecular machinery that DCs use to carry out efferocytosis and antigen presentation in vivo has not yet been reported (below). In the context of atherosclerosis, DC efferocytosis may have a particularly important influence on plaque progression. In general, efferocytosis results in suppression of inflammation and suppression of DC maturation. Moreover, DC mediated efferocytosis of lesional apoptotic cells could prevent secondary cellular necrosis, which is a major pro-inflammatory signal that accelerates atherosclerotic lesion development as well as necrotic core formation [62]. Additionally, efferocytosis of lipid-laden apoptotic foam cells by DCs, followed by their migration out of earlier lesions, could play a critical role in removing oxidized lipids, cholesterol, and other pro-inflammatory damage-associated 
molecular patterns. In this context, several studies have demonstrated that efferocytosis by macrophages plays a critical role in inflammation resolution and prevention of necrotic core formation in advanced atherosclerotic plaques [63-66]. However, there are no published studies till date that address the role of efferocytosis by intimal DCs in antigen acquisition, inflammation resolution, or necrotic core formation. As mentioned above, a major hurdle in the conduct of such studies is the lack of knowledge of the efferocytosis receptors utilized by DCs in vivo. For example, previous in vitro studies have identified CD36, av $\beta 5$, and Axl/ Tyro to mediate DC efferocytosis $[67,68]$. However, the relevance of these receptors in vivo in DC efferocytosis is not known. Future studies are necessary to identify the molecular mechanisms of DC efferocytosis in vivo so that molecular-genetic causation experiments can be conducted, i.e., by specifically disrupting DC efferocytosis and then assaying $\mathrm{T}$ cell activation and inflammation resolution in atherosclerosis.

As alluded to earlier, the accumulation of mature DCs in advanced atherosclerotic plaque could have several consequences, including amplification of local inflammatory processes, extracellular matrix degradation, and promotion of necrotic core development [62, 69]. With regard to the latter point, it is interesting to note that DCs lose their efferocytosis ability upon maturation [67]. Thus, the accumulation of mature DCs in advanced atherosclerotic lesions [10] could result in pockets of defective efferocytosis leading to focal necrosis. Consistent with this idea, we observed the presence of mature DCs not only in the shoulder region of the advanced murine atherosclerotic plaque but also adjoining the necrotic cores in these lesions (unpublished observations). Additional studies using models of defective DC maturation, such as $\mathrm{CD} 11 \mathrm{cCre}{ }^{+} \mathrm{MyD} 88^{\mathrm{fl} f \mathrm{fl}}$ mice [42], or models in which emigration of mature DCs from the advanced plaque might be restored, e.g., through restoration of CCR7, will be required to understand the specific contribution of mature DCs in advanced atherosclerosis.

\section{DC-based vaccine strategies}

The understanding that atherosclerosis is a chronic inflammatory disorder that has an autoimmune component shaped by both cellular as well as humoral immunity has raised the possibility of using vaccination approaches in the treatment of atherosclerosis [43]. Early seminal studies demonstrated that immunization of rabbits or mice with native or oxidized LDL resulted in considerable protection against atherosclerosis [70-72]. Considering the complex nature of the LDL particle, recent efforts are focused on identifying minimal LDLrelated epitopes, both lipid and protein, that would elicit potent immune response against atherosclerosis [43].

Given the central role of DCs in the activation of cellular as well as humoral immunity, recent efforts are focused on developing DC-based vaccination strategies against atherosclerosis. For example, intravenous injection of exogenous oxidized LDL-loaded DCs resulted in attenuation of flow-induced atherosclerosis and stabilization of plaque phenotype in carotid arteries of mice [71]. In an interesting alternate approach, DCs loaded with apoB100 protein were treated with the immunosuppressive cytokine IL-10, which is known to induce a tolerogenic phenotype in DCs. The injection of these tolerogenic apoB100containing DCs led to decreased atherosclerotic lesion progression, decreased systemic inflammation, and decreased lesional infiltration of CD4+ T cells in human apoB100transgenic $L d l r^{-/-}$mice [73]. These effects were likely due to induction of the protective Treg cell response. These pre-clinical studies suggest that DC-based vaccination may be a powerful approach for eliciting protective Treg cell response in the treatment of atherosclerosis. To accomplish this goal, new approaches are needed to identify the antigen specificity of reactive $\mathrm{T}$ cells in atherosclerotic lesions so that efficient immunosuppressive vaccines can be designed. 


\section{Acknowledgments}

I.T. is supported by National Institutes of Health grants HL106019, HL075662, and HL054591.

\section{References}

1. Tabas I, Williams KJ, Boren J. Subendothelial lipoprotein retention as the initiating process in atherosclerosis: update and therapeutic implications. Circulation. 2007; 116:1832-1844. [PubMed: 17938300]

2. Moore KJ, Tabas I. Macrophages in the pathogenesis of atherosclerosis. Cell. 2011; 145:341-355. [PubMed: 21529710]

3. Virmani R, Burke AP, Farb A, Kolodgie FD. Pathology of the vulnerable plaque. J Am Coll Cardiol. 2006; 47:C13-C18. [PubMed: 16631505]

4. Bobryshev YV, Lord RS. S-100 positive cells in human arterial intima and in atherosclerotic lesions. Cardiovasc Res. 1995; 29:689-696. [PubMed: 7606759]

5. Choi JH, Do Y, Cheong C, Koh H, Boscardin SB, Oh YS, Bozzacco L, Trumpfheller C, Park CG, Steinman RM. Identification of antigen-presenting dendritic cells in mouse aorta and cardiac valves. J Exp Med. 2009; 206:497-505. [PubMed: 19221394]

6. Miller JC, Brown BD, Shay T, Gautier EL, Jojic V, Cohain A, Pandey G, Leboeuf M, Elpek KG, Helft J, Hashimoto D, Chow A, Price J, Greter M, Bogunovic M, Bellemare-Pelletier A, Frenette PS, Randolph GJ, Turley SJ, Merad M. Deciphering the transcriptional network of the dendritic cell lineage. Nat Immunol. 2012; 13:888-899. [PubMed: 22797772]

7. Cheong C, Choi JH. Dendritic cells and regulatory T cells in atherosclerosis. Mol Cells. 2012; 34:341-347. [PubMed: 22752759]

8. Gerner MY, Kastenmuller W, Ifrim I, Kabat J, Germain RN. Histocytometry: a method for highly multiplex quantitative tissue imaging analysis applied to dendritic cell subset microanatomy in lymph nodes. Immunity. 2012; 37:364-376. [PubMed: 22863836]

9. Cho HJ, Shashkin P, Gleissner CA, Dunson D, Jain N, Lee JK, Miller Y, Ley K. Induction of dendritic cell-like phenotype in macrophages during foam cell formation. Physiol Genomics. 2007; 29:149-160. [PubMed: 17244792]

10. Yilmaz A, Lochno M, Traeg F, Cicha I, Reiss C, Stumpf C, Raaz D, Anger T, Amann K, Probst T, Ludwig J, Daniel WG, Garlichs CD. Emergence of dendritic cells in rupture-prone regions of vulnerable carotid plaques. Atherosclerosis. 2004; 176:101-110. [PubMed: 15306181]

11. Jongstra-Bilen J, Haidari M, Zhu SN, Chen M, Guha D, Cybulsky MI. Low-grade chronic inflammation in regions of the normal mouse arterial intima predisposed to atherosclerosis. J Exp Med. 2006; 203:2073-2083. [PubMed: 16894012]

12. Choi JH, Cheong C, Dandamudi DB, Park CG, Rodriguez A, Mehandru S, Velinzon K, Jung IH, Yoo JY, Oh GT, Steinman RM. Flt3 signaling-dependent dendritic cells protect against atherosclerosis. Immunity. 2011; 35:819-831. [PubMed: 22078798]

13. Tacke F, Alvarez D, Kaplan TJ, Jakubzick C, Spanbroek R, Llodra J, Garin A, Liu J, Mack M, van Rooijen N, Lira SA, Habenicht AJ, Randolph GJ. Monocyte subsets differentially employ CCR2, CCR5, and CX3CR1 to accumulate within atherosclerotic plaques. J Clin Invest. 2007; 117:185194. [PubMed: 17200718]

14. Yona S, Jung S. Monocytes: subsets, origins, fates and functions. Curr Opin Hematol. 2010; 17:53-59. [PubMed: 19770654]

15. Liu P, Yu YR, Spencer JA, Johnson AE, Vallanat CT, Fong AM, Patterson C, Patel DD. CX3CR1 deficiency impairs dendritic cell accumulation in arterial intima and reduces atherosclerotic burden. Arterioscler Thromb Vasc Biol. 2008; 28:243-250. [PubMed: 18079406]

16. Doring Y, Manthey HD, Drechsler M, Lievens D, Megens RT, Soehnlein O, Busch M, Manca M, Koenen RR, Pelisek J, Daemen MJ, Lutgens E, Zenke M, Binder CJ, Weber C, Zernecke A. Autoantigenic protein-DNA complexes stimulate plasmacytoid dendritic cells to promote atherosclerosis. Circulation. 2012; 125:1673-1683. [PubMed: 22388324]

17. Weber C, Meiler S, Doring Y, Koch M, Drechsler M, Megens RT, Rowinska Z, Bidzhekov K, Fecher C, Ribechini E, van Zandvoort MA, Binder CJ, Jelinek I, Hristov M, Boon L, Jung S, Korn 
T, Lutz MB, Forster I, Zenke M, Hieronymus T, Junt T, Zernecke A. CCL17-expressing dendritic cells drive atherosclerosis by restraining regulatory $\mathrm{T}$ cell homeostasis in mice. $\mathrm{J}$ Clin Invest. 2011; 121:2898-2910. [PubMed: 21633167]

18. Zhu SN, Chen M, Jongstra-Bilen J, Cybulsky MI. GM-CSF regulates intimal cell proliferation in nascent atherosclerotic lesions. J Exp Med. 2009; 206:2141-2149. [PubMed: 19752185]

19. Greter M, Helft J, Chow A, Hashimoto D, Mortha A, Agudo-Cantero J, Bogunovic M, Gautier EL, Miller J, Leboeuf M, Lu G, Aloman C, Brown BD, Pollard JW, Xiong H, Randolph GJ, Chipuk JE, Frenette PS, Merad M. GM-CSF controls nonlymphoid tissue dendritic cell homeostasis but is dispensable for the differentiation of inflammatory dendritic cells. Immunity. 2012; 36:10311046. [PubMed: 22749353]

20. Satpathy AT, Kc W, Albring JC, Edelson BT, Kretzer NM, Bhattacharya D, Murphy TL, Murphy KM. Zbtb46 expression distinguishes classical dendritic cells and their committed progenitors from other immune lineages. J Exp Med. 2012; 209:1135-1152. [PubMed: 22615127]

21. Meredith MM, Liu K, Darrasse-Jeze G, Kamphorst AO, Schreiber HA, Guermonprez P, Idoyaga J, Cheong C, Yao KH, Niec RE, Nussenzweig MC. Expression of the zinc finger transcription factor zDC (Zbtb46, Btbd4) defines the classical dendritic cell lineage. J Exp Med. 2012; 209:11531165. [PubMed: 22615130]

22. Paulson KE, Zhu SN, Chen M, Nurmohamed S, Jongstra-Bilen J, Cybulsky MI. Resident intimal dendritic cells accumulate lipid and contribute to the initiation of atherosclerosis. Circ Res. 2010; 106:383-390. [PubMed: 19893012]

23. Gautier EL, Huby T, Saint-Charles F, Ouzilleau B, Pirault J, Deswaerte V, Ginhoux F, Miller ER, Witztum JL, Chapman MJ, Lesnik P. Conventional dendritic cells at the crossroads between immunity and cholesterol homeostasis in atherosclerosis. Circulation. 2009; 119:2367-2375. [PubMed: 19380622]

24. Virginie Deswaerte TH, Saint-Charles Flora, Proschogo Nicolas, Beliard Sophie, Pirault John, Lesnik Philippe, Jessup Wendy. Influence of dendritic cells on cholesterol absorption and excretion: implication in atherogenesis. Arterioscler Thromb Vasc Biol. 2012; 32:A307.

25. Spann NJ, Garmire LX, McDonald JG, Myers DS, Milne SB, Shibata N, Reichart D, Fox JN, Shaked I, Heudobler D, Raetz CR, Wang EW, Kelly SL, Sullards MC, Murphy RC, Merrill AH Jr, Brown HA, Dennis EA, Li AC, Ley K, Tsimikas S, Fahy E, Subramaniam S, Quehenberger O, Russell DW, Glass CK. Regulated accumulation of desmosterol integrates macrophage lipid metabolism and inflammatory responses. Cell. 2012; 151:138-152. [PubMed: 23021221]

26. Alderman CJJ, Bunyard PR, Chain BM, Foreman JC, Leake DS, Katz DR. Effects of oxidised low density lipoprotein on dendritic cells: a possible immunoregulatory component of the atherogenic micro-environment? Cardiovasc Res. 2002; 55:806-819. [PubMed: 12176130]

27. Zaguri R, Verbovetski I, Atallah M, Trahtemberg U, Krispin A, Nahari E, Leitersdorf E, Mevorach D. 'Danger' effect of low-density lipoprotein (LDL) and oxidized LDL on human immature dendritic cells. Clin Exp Immunol. 2007; 149:543-552. [PubMed: 17645766]

28. Nickel T, Schmauss D, Hanssen H, Sicic Z, Krebs B, Jankl S, Summo C, Fraunberger P, Walli AK, Pfeiler S, Weis M. oxLDL uptake by dendritic cells induces upregulation of scavenger-receptors, maturation and differentiation. Atherosclerosis. 2009; 205:442-450. [PubMed: 19203752]

29. Packard RR, Maganto-Garcia E, Gotsman I, Tabas I, Libby P, Lichtman AH. CD11c(+) dendritic cells maintain antigen processing, presentation capabilities, and CD4(+) T-cell priming efficacy under hypercholesterolemic conditions associated with atherosclerosis. Circ Res. 2008; 103:965973. [PubMed: 18832748]

30. Angeli V, Llodra J, Rong JX, Satoh K, Ishii S, Shimizu T, Fisher EA, Randolph GJ. Dyslipidemia associated with atherosclerotic disease systemically alters dendritic cell mobilization. Immunity. 2004; 21:561-574. [PubMed: 15485633]

31. Trogan E, Feig JE, Dogan S, Rothblat GH, Angeli V, Tacke F, Randolph GJ, Fisher EA. Gene expression changes in foam cells and the role of chemokine receptor CCR7 during atherosclerosis regression in ApoE-deficient mice. Proc Natl Acad Sci U S A. 2006; 103:3781-3786. [PubMed: 16537455]

32. Potteaux S, Gautier EL, Hutchison SB, van Rooijen N, Rader DJ, Thomas MJ, Sorci-Thomas MG, Randolph GJ. Suppressed monocyte recruitment drives macrophage removal from atherosclerotic 
plaques of Apoe ${ }^{-/-}$mice during disease regression. J Clin Invest. 2011; 121:2025-2036. [PubMed: 21505265]

33. Forster R, Davalos-Misslitz AC, Rot A. CCR7 and its ligands: balancing immunity and tolerance. Nat Rev Immunol. 2008; 8:362-371. [PubMed: 18379575]

34. Feig JE, Shang Y, Rotllan N, Vengrenyuk Y, Wu C, Shamir R, Torra IP, Fernandez-Hernando C, Fisher EA, Garabedian MJ. Statins promote the regression of atherosclerosis via activation of the CCR7-dependent emigration pathway in macrophages. PLoS One. 2011; 6:e28534. [PubMed: 22163030]

35. van Gils JM, Derby MC, Fernandes LR, Ramkhelawon B, Ray TD, Rayner KJ, Parathath S, Distel E, Feig JL, Alvarez-Leite JI, Rayner AJ, McDonald TO, O’Brien KD, Stuart LM, Fisher EA, Lacy-Hulbert A, Moore KJ. The neuroimmune guidance cue netrin-1 promotes atherosclerosis by inhibiting the emigration of macrophages from plaques. Nat Immunol. 2012; 13:136-143. [PubMed: 22231519]

36. Hansson GK, Hermansson A. The immune system in atherosclerosis. Nat Immunol. 2011; 12:204212. [PubMed: 21321594]

37. Buono C, Pang H, Uchida Y, Libby P, Sharpe AH, Lichtman AH. B7-1/B7-2 costimulation regulates plaque antigen-specific $\mathrm{T}$-cell responses and atherogenesis in low-density lipoprotein receptor-deficient mice. Circulation. 2004; 109:2009-2015. [PubMed: 15096453]

38. Sun J, Hartvigsen K, Chou MY, Zhang Y, Sukhova GK, Zhang J, Lopez-Ilasaca M, Diehl CJ, Yakov N, Harats D, George J, Witztum JL, Libby P, Ploegh H, Shi GP. Deficiency of antigenpresenting cell invariant chain reduces atherosclerosis in mice. Circulation. 2010; 122:808-820. [PubMed: 20697023]

39. Salomon B, Lenschow DJ, Rhee L, Ashourian N, Singh B, Sharpe A, Bluestone JA. B7/CD28 costimulation is essential for the homeostasis of the $\mathrm{CD} 4{ }^{+} \mathrm{CD} 25^{+}$immunoregulatory $\mathrm{T}$ cells that control autoimmune diabetes. Immunity. 2000; 12:431-440. [PubMed: 10795741]

40. Ait-Oufella H, Salomon BL, Potteaux S, Robertson AK, Gourdy P, Zoll J, Merval R, Esposito B, Cohen JL, Fisson S, Flavell RA, Hansson GK, Klatzmann D, Tedgui A, Mallat Z. Natural regulatory $T$ cells control the development of atherosclerosis in mice. Nat Med. 2006; 12:178-180. [PubMed: 16462800]

41. Hou B, Reizis B, DeFranco AL. Toll-like receptors activate innate and adaptive immunity by using dendritic cell-intrinsic and -extrinsic mechanisms. Immunity. 2008; 29:272-282. [PubMed: 18656388]

42. Subramanian M, Thorp E, Hansson GK, Tabas I. Treg-mediated suppression of atherosclerosis requires MYD88 signaling in DCs. J Clin Invest. 2013; 123:179-188. [PubMed: 23257360]

43. Hansson GK, Nilsson J. Vaccination against atherosclerosis? Induction of atheroprotective immunity. Semin Immunopathol. 2009; 31:95-101. [PubMed: 19468734]

44. Paulsson G, Zhou X, Tornquist E, Hansson GK. Oligoclonal T cell expansions in atherosclerotic lesions of apolipoprotein E-deficient mice. Arterioscler Thromb Vasc Biol. 2000; 20:10-17. [PubMed: 10634795]

45. Erbel C, Sato K, Meyer FB, Kopecky SL, Frye RL, Goronzy JJ, Weyand CM. Functional profile of activated dendritic cells in unstable atherosclerotic plaque. Basic Res Cardiol. 2007; 102:123-132. [PubMed: 17136419]

46. Koltsova EK, Garcia Z, Chodaczek G, Landau M, McArdle S, Scott SR, von Vietinghoff S, Galkina E, Miller YI, Acton ST, Ley K. Dynamic T cell-APC interactions sustain chronic inflammation in atherosclerosis. J Clin Invest. 2012; 122:3114-3126. [PubMed: 22886300]

47. Grabner R, Lotzer K, Dopping S, Hildner M, Radke D, Beer M, Spanbroek R, Lippert B, Reardon CA, Getz GS, Fu YX, Hehlgans T, Mebius RE, van der Wall M, Kruspe D, Englert C, Lovas A, Hu D, Randolph GJ, Weih F, Habenicht AJ. Lymphotoxin beta receptor signaling promotes tertiary lymphoid organogenesis in the aorta adventitia of aged $\mathrm{ApoE}^{-/-}$mice. J Exp Med. 2009; 206:233-248. [PubMed: 19139167]

48. Maganto-Garcia E, Bu DX, Tarrio ML, Alcaide P, Newton G, Griffin GK, Croce KJ, Luscinskas FW, Lichtman AH, Grabie N. Foxp $3^{+}$-inducible regulatory T cells suppress endothelial activation and leukocyte recruitment. J Immunol. 2011; 187:3521-3529. [PubMed: 21873519] 
49. Robertson AK, Rudling M, Zhou X, Gorelik L, Flavell RA, Hansson GK. Disruption of TGF-beta signaling in T cells accelerates atherosclerosis. J Clin Invest. 2003; 112:1342-1350. [PubMed: 14568988]

50. Gotsman I, Gupta R, Lichtman AH. The influence of the regulatory T lymphocytes on atherosclerosis. Arterioscler Thromb Vasc Biol. 2007; 27:2493-2495. [PubMed: 17901372]

51. Lin X, Chen M, Liu Y, Guo Z, He X, Brand D, Zheng SG. Advances in distinguishing natural from induced Foxp3(+) regulatory T cells. Int J Clin Exp Pathol. 2013; 6:116-123. [PubMed: 23329997]

52. Sugimoto N, Oida T, Hirota K, Nakamura K, Nomura T, Uchiyama T, Sakaguchi S. Foxp3dependent and -independent molecules specific for $\mathrm{CD} 25^{+} \mathrm{CD} 4^{+}$natural regulatory $\mathrm{T}$ cells revealed by DNA microarray analysis. Int Immunol. 2006; 18:1197-1209. [PubMed: 16772372]

53. Weiss JM, Bilate AM, Gobert M, Ding Y, Curotto de Lafaille MA, Parkhurst CN, Xiong H, Dolpady J, Frey AB, Ruocco MG, Yang Y, Floess S, Huehn J, Oh S, Li MO, Niec RE, Rudensky AY, Dustin ML, Littman DR, Lafaille JJ. Neuropilin 1 is expressed on thymus-derived natural regulatory T cells, but not mucosa-generated induced Foxp3+ T reg cells. J Exp Med. 2012; 209(1723-42):S1.

54. Bour-Jordan H, Bluestone JA. Regulating the regulators: costimulatory signals control the homeostasis and function of regulatory T cells. Immunol Rev. 2009; 229:41-66. [PubMed: 19426214]

55. Coombes JL, Siddiqui KR, Arancibia-Carcamo CV, Hall J, Sun CM, Belkaid Y, Powrie F. A functionally specialized population of mucosal CD103+ DCs induces Foxp3+ regulatory $\mathrm{T}$ cells via a TGF-beta and retinoic acid-dependent mechanism. J Exp Med. 2007; 204:1757-1764. [PubMed: 17620361]

56. Beaty SR, Rose CE Jr, Sung SS. Diverse and potent chemokine production by lung CD11bhigh dendritic cells in homeostasis and in allergic lung inflammation. J Immunol. 2007; 178:18821895. [PubMed: 17237439]

57. Niessner A, Sato K, Chaikof EL, Colmegna I, Goronzy JJ, Weyand CM. Pathogen-sensing plasmacytoid dendritic cells stimulate cytotoxic T-cell function in the atherosclerotic plaque through interferon-alpha. Circulation. 2006; 114:2482-2489. [PubMed: 17116765]

58. Goossens P, Gijbels MJ, Zernecke A, Eijgelaar W, Vergouwe MN, van der Made I, Vanderlocht J, Beckers L, Buurman WA, Daemen MJ, Kalinke U, Weber C, Lutgens E, de Winther MP. Myeloid type I interferon signaling promotes atherosclerosis by stimulating macrophage recruitment to lesions. Cell Metab. 2010; 12:142-153. [PubMed: 20674859]

59. Niessner A, Shin MS, Pryshchep O, Goronzy JJ, Chaikof EL, Weyand CM. Synergistic proinflammatory effects of the antiviral cytokine interferon-alpha and Toll-like receptor 4 ligands in the atherosclerotic plaque. Circulation. 2007; 116:2043-2052. [PubMed: 17938289]

60. Daissormont IT, Christ A, Temmerman L, Sampedro Millares S, Seijkens T, Manca M, Rousch M, Poggi M, Boon L, van der Loos C, Daemen M, Lutgens E, Halvorsen B, Aukrust P, Janssen E, Biessen EA. Plasmacytoid dendritic cells protect against atherosclerosis by tuning T-cell proliferation and activity. Circ Res. 2011; 109:1387-1395. [PubMed: 22021930]

61. Heath WR, Carbone FR. Cross-presentation in viral immunity and self-tolerance. Nat Rev Immunol. 2001; 1:126-134. [PubMed: 11905820]

62. Tabas I. Macrophage death and defective inflammation resolution in atherosclerosis. Nat Rev Immunol. 2010; 10:36-46. [PubMed: 19960040]

63. Thorp E, Cui D, Schrijvers DM, Kuriakose G, Tabas I. Mertk receptor mutation reduces efferocytosis efficiency and promotes apoptotic cell accumulation and plaque necrosis in atherosclerotic lesions of apoe-/- mice. Arterioscler Thromb Vasc Biol. 2008; 28:1421-1428. [PubMed: 18451332]

64. Ait-Oufella H, Pouresmail V, Simon T, Blanc-Brude O, Kinugawa K, Merval R, Offenstadt G, Leseche G, Cohen PL, Tedgui A, Mallat Z. Defective mer receptor tyrosine kinase signaling in bone marrow cells promotes apoptotic cell accumulation and accelerates atherosclerosis. Arterioscler Thromb Vasc Biol. 2008; 28:1429-1431. [PubMed: 18467644] 
65. Yancey PG, Blakemore J, Ding L, Fan D, Overton CD, Zhang Y, Linton MF, Fazio S. Macrophage LRP-1 controls plaque cellularity by regulating efferocytosis and Akt activation. Arterioscler Thromb Vasc Biol. 2010; 30:787-795. [PubMed: 20150557]

66. Ait-Oufella H, Kinugawa K, Zoll J, Simon T, Boddaert J, Heeneman S, Blanc-Brude O, Barateau V, Potteaux S, Merval R, Esposito B, Teissier E, Daemen MJ, Leseche G, Boulanger C, Tedgui A, Mallat Z. Lactadherin deficiency leads to apoptotic cell accumulation and accelerated atherosclerosis in mice. Circulation. 2007; 115:2168-2177. [PubMed: 17420351]

67. Albert ML, Pearce SF, Francisco LM, Sauter B, Roy P, Silverstein RL, Bhardwaj N. Immature dendritic cells phagocytose apoptotic cells via alphavbeta5 and CD36, and cross-present antigens to cytotoxic T lymphocytes. J Exp Med. 1998; 188:1359-1368. [PubMed: 9763615]

68. Seitz HM, Camenisch TD, Lemke G, Earp HS, Matsushima GK. Macrophages and dendritic cells use different Axl/Mertk/Tyro3 receptors in clearance of apoptotic cells. J Immunol. 2007; 178:5635-5642. [PubMed: 17442946]

69. Thorp E, Tabas I. Mechanisms and consequences of efferocytosis in advanced atherosclerosis. J Leukoc Biol. 2009; 86:1089-1095. [PubMed: 19414539]

70. Ameli S, Hultgardh-Nilsson A, Regnstrom J, Calara F, Yano J, Cercek B, Shah PK, Nilsson J. Effect of immunization with homologous LDL and oxidized LDL on early atherosclerosis in hypercholesterolemic rabbits. Arterioscler Thromb Vasc Biol. 1996; 16:1074-1079. [PubMed: 8696949]

71. Habets KL, van Puijvelde GH, van Duivenvoorde LM, van Wanrooij EJ, de Vos P, Tervaert JW, van Berkel TJ, Toes RE, Kuiper J. Vaccination using oxidized low-density lipoprotein-pulsed dendritic cells reduces atherosclerosis in LDL receptor-deficient mice. Cardiovasc Res. 2010; 85:622-630. [PubMed: 19819882]

72. Palinski W, Miller E, Witztum JL. Immunization of low density lipoprotein (LDL) receptordeficient rabbits with homologous malondialdehyde-modified LDL reduces atherogenesis. Proc Natl Acad Sci U S A. 1995; 92:821-825. [PubMed: 7846059]

73. Hermansson A, Johansson DK, Ketelhuth DF, Andersson J, Zhou X, Hansson GK. Immunotherapy with tolerogenic apolipoprotein B-100-loaded dendritic cells attenuates atherosclerosis in hypercholesterolemic mice. Circulation. 2011; 123:1083-1091. [PubMed: 21357823] 


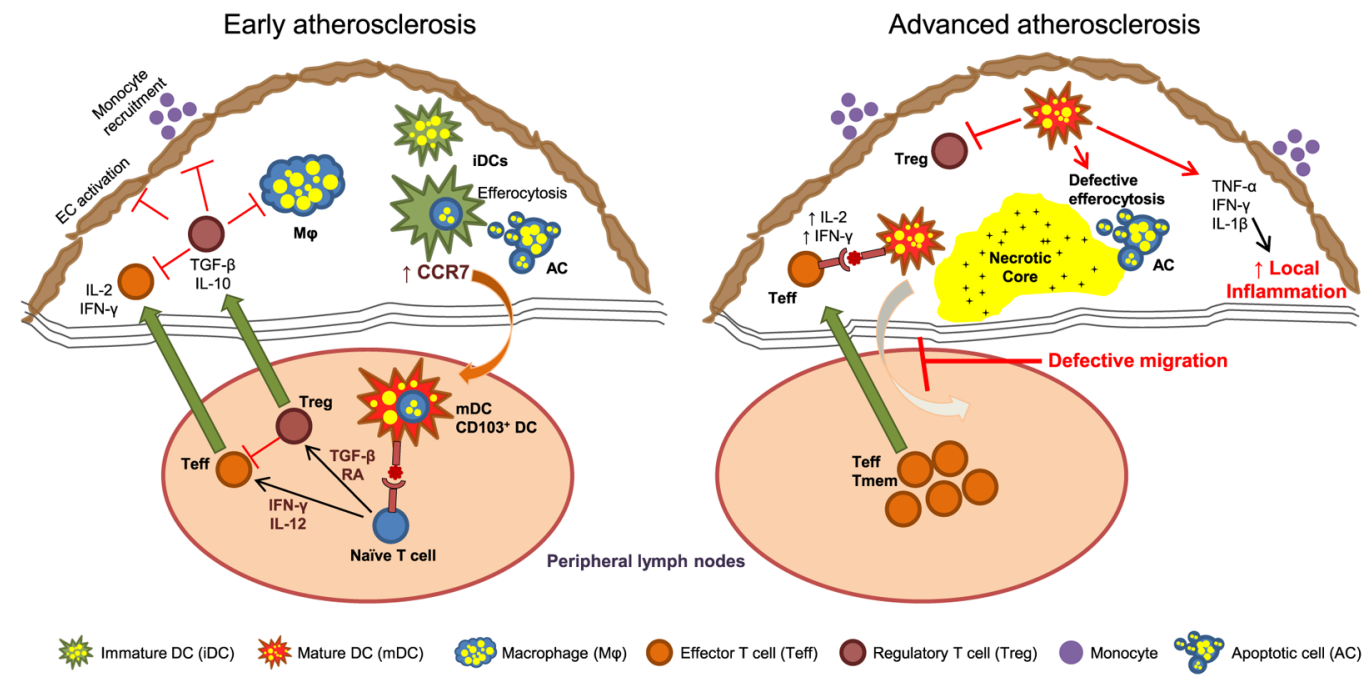

Fig. 1.

Proposed roles for DCs in the pathogenesis of early and advanced atherosclerosis. DCs in early atherosclerotic lesions become foam cells, most likely via the uptake of lipoproteins and lipid-laden apoptotic cells. Upon maturation and expression of CCR7, DCs emigrate from lesions into the draining lymph node to present antigen to and activate naïve $\mathrm{T}$ cells. The naïve $\mathrm{T}$ cells differentiate into Treg or Teff depending on the specific cytokine environment under which they are primed. Teff cells secrete pro-inflammatory cytokines and thereby have the capacity to promote atherogenesis, but this process is counteracted by Tregs. Tregs also inhibit the activation of endothelial cells and macrophages and block new monocyte recruitment via secretion of anti-inflammatory cytokines TGF- $\beta$ and IL- 10 .

However, in advanced atherosclerotic lesions, the emigration of DCs from the plaque is defective, perhaps because of the deficient upregulation of CCR7 or negative guidance cues. The retention of mature DCs in the plaque can lead to enhanced local inflammation via secretion of pro-inflammatory cytokines as well as activation of effector/ memory $\mathrm{T}$ cells. Moreover, as mature DCs are poor efferocytes, their accumulation in advanced atherosclerotic plaque could, in theory, lead to pockets of defective efferocytosis with consequent expansion of the necrotic core 